\title{
The Application of Rapid Prototyping Technology and Quality Functional Deployment (QFD) approach in enhancing the Endotracheal Tube Holder Model in Medical Application
}

\author{
WAY Yusoff ${ }^{\mathrm{a}}$, A Hadi Mohamad ${ }^{\mathrm{b}}$, Aesyhah ${ }^{\mathrm{c}}$ \\ a,c Kulliyyah of Engineering, International Islamic University, Malaysia \\ ${ }^{\mathrm{b}}$ Kulliyyah of Medicine, International Islamic University, Malaysia \\ ayusmawiza@iium.edu.my (corresponding author)
}

\begin{abstract}
This paper presents a development of a current design the Endotracheal tube holding device. At present, the medical teams have faced a lot of problems when doing the endotracheal intubation. Misplacement of endotracheal tube into the esophagus and extubation due to patient's movement are among the problems by surgeons during medical treatment. This is important as the successful management of the potential risk can reduce the number of patients who suffer a serious consequence of endtracheal tube therapy such as a potential risk to patient safety, with associated risks varying from minor complications to death. This paper presents a product design specification for endotracheal tube-holding device is translated from user's requirements by employing Quality Functional Deployment (QFD). Several design concepts are generated by using CATIA software to be evaluated by endotracheal tube-holding device users for concept selection. Selection of design concept was done in two phases which are concept screening and concept scoring. For selecting the design concept for further development, a prototype of endotracheal tube was fabricated by using Fused Deposition Modelling (FDM).
\end{abstract}

\section{Introduction}

An endotracheal tube is a breathing tube in curved shape and commonly used in critical medicine for many patients in operation theatre, intensive care units (ICU) and emergency departments as shown in figure 1. According to the medical procedure, endotracheal intubation is the placement of a tube into the trachea (windpipe) in order to maintain an open airway in patients who are unconscious or unable to breathe on their own as shown in figure 2. Oxygen, anesthetics, or other gaseous medications can be delivered through the tube [1].

Prior to this study, There were some research focused on the endotracheal tube and respiratory care, the role of the endotracheal tube cuff in microaspiration and management of a severed endotracheal tube.[1-4]. However the problem of the existing design endtracheal tube holder (ETT) when doing the endotracheal intubation causing inappropriate fixation of an endotracheal tube which results the patients experienced difficult tracheostorm into the esophagus and extubation are not thoroughly investigated.

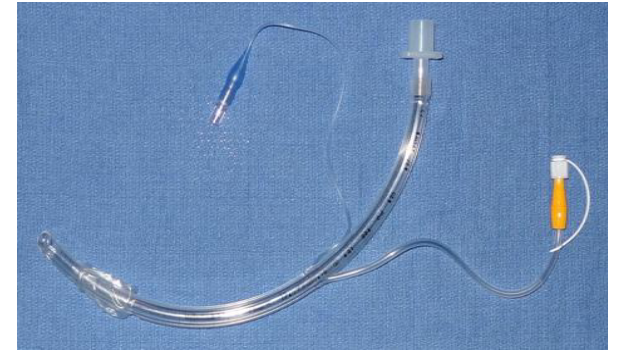

Figure 1. Cuffed endotracheal tube [ 4 ]

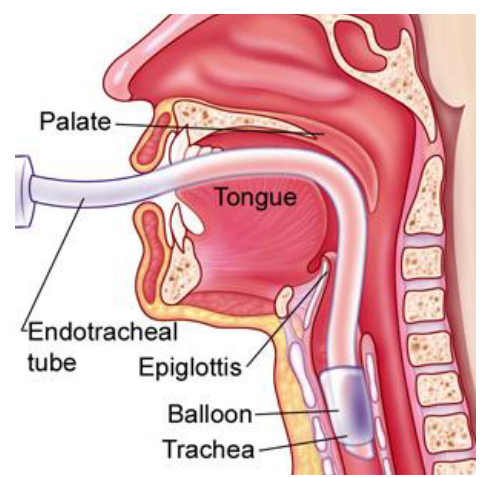

Figure 2. Endotracheal tube placement [3] 


\section{Rapid Prototyping Technology In Medical Engineering}

Nowadays, product development and the design process in medical fields are mostly associated with Rapid Prototyping (RP) technologies. In general, RP is the process of conversion from 3D Computer Aided Design (CAD) virtual models into physical models without the need for specialized tooling or fixtures. The FDM machine is used to generate the physical model of prototype was used to fabricate the prototype Endtracheal tube holder of since RP can offers great deals in saving cost, time, and material usage for the tested and producible model before being commercialized. The advantages of employing FDM are good layer bonding with ABS materials, fast small part production and Good for parts with thin walls.

In the medical applications, the existence of rapid prototyping as technology originating from engineering is appeasing several progresses. Moreover, it is proved that many doctors and surgeons have used the technologies successfully. Therefore, the use of RP in medicine is increasing because of the higher possibility to achieve the planning and the surgical simulation being used for a three dimensional biomodel [5-6].

\section{Quality Function Deployment (QFD)}

This research demonstrates how Quality Function Deployment (QFD) can be applied to medical devise by retrospectively applying the methods in enhancing the Endtracheal tube holder (ETT) model for Medical for medical application. Prior to this research, several researchers had applied Quality function deployment (QFD) to identify the elements of the design of the medical devices that will satisfy the customer's need [79]. This method determines the important set of requirement for each phase of Product Development Process (PDP) planning and uses them to identify the set of technical characteristics of each phase that most contribute to satisfying the requirements. The implementation of QFD consists of four phases; define and prioritize customer needs, analyze competitive opportunities, plan a product to respond to needs and opportunities and establish critical characteristic target values. Then all the customer's needs and requirements then will be summarized and put into product planning matrix or "house of quality" [8].

\section{Methodology}

The questionnaire for identifying the basic design features of endotracheal tube holder was distributed to surgeons, nurse and medic's students at the government and private hospitals in Malaysia. The QFD for designing the endotracheal tube holder was constructed in order to focus on the required needs by the customer. From the results of the survey, the researcher was able to list down the customer requirements and then gives the weight factor according to the responses provided by the respondents. The engineering characteristics are the important characteristics in engineering view for manufacturing the product. Several criteria were identified for selecting which design satisfied the user requirements. These selection criteria were then arranged from the most important to the least important requirement. After the selection criteria were identified, the concept screening was then developed. The concept scoring was done in order to narrow down the range of concepts under consideration. After concept screening, concept scoring was then established. At this stage, the concept with the highest ranking was chosen.

\section{Results and Analysis}

After the QFD was constructed, the researcher found out that the most important requirement that needs to be focused on is to make the design simpler as shown in Table 1. This could be because the current endotracheal tube holder that is available in the market has a complicated design. A design that is complicated will be difficult to be manufactured and thus, will cause the manufacturing cost to be high. The second important requirement is the external dimensions of the tube holder. The reason for this could be because the holder needs to hold the tube tightly. If the external dimension of the holder is not accurate, the holder will loosely hold the endotracheal tube and thus, will cause the endotracheal tube to be extubated by itself. The third important requirement is the number of sizes. This could be because the endotracheal tube has many different sizes. The sizes are according to the age of the patients. For adults, the size of the endotracheal tube is larger than for the children. The least important requirement is the toughness of the material

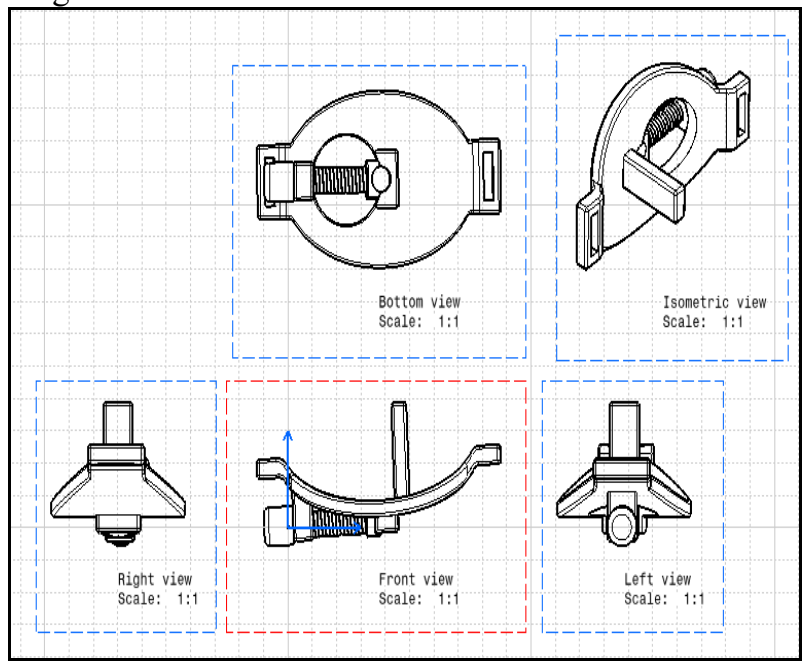

Figure 3. Design Concept

From the results obtained from the concept scoring and concept screening, the most potential concept was developed based on the closest criteria required by the users. The final design concept is as shown in figure 3. Next, fabrication of prototype by using the FDM machine (rapid prototyping technology) which took 3 hours to complete the new concept of the endtracheal tube holder model as shown in figure 4. 


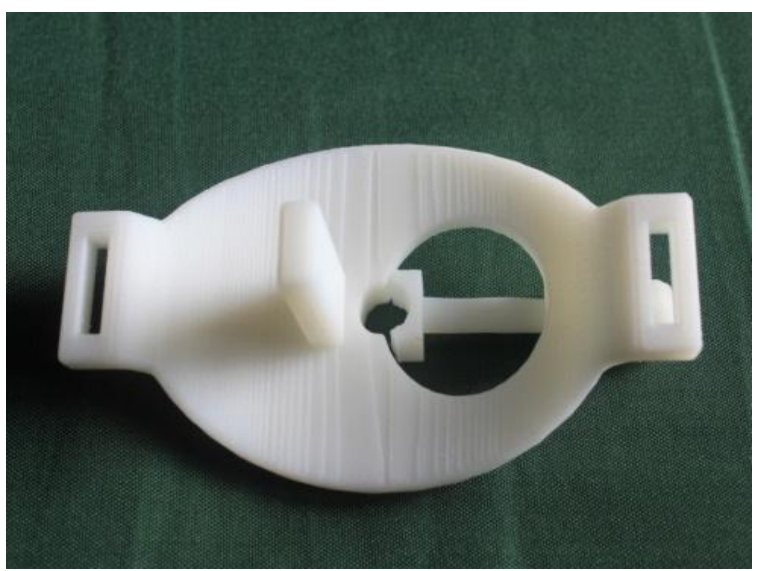

Figure 4. Final Design Concept

Table 1 QFD of Endtracheal tube holder model

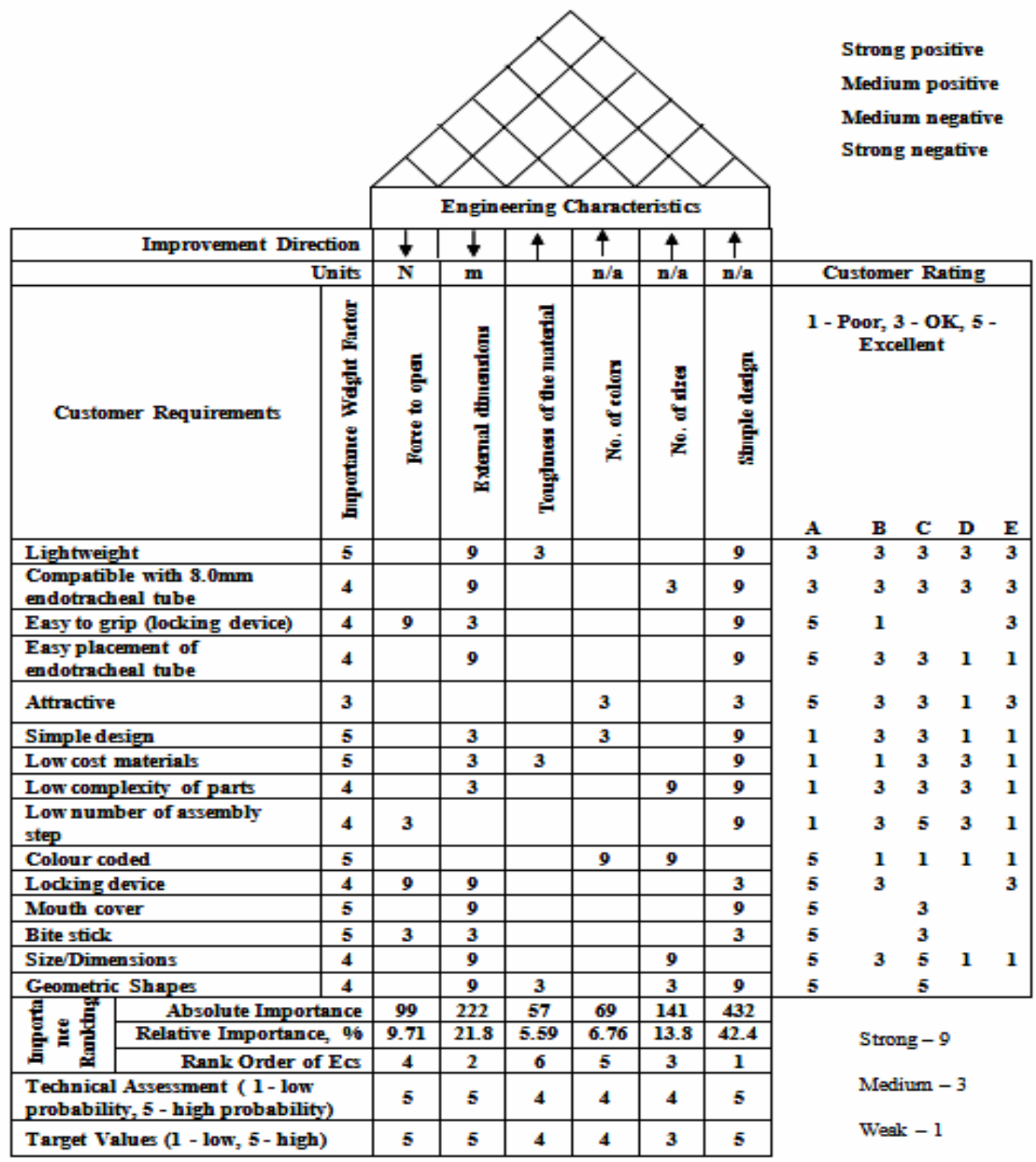

\section{Conclusion}

This research investigated the basic design elements of the endotracheal tube holder. By employing product design and development approach known as Quality functional Deployment (QFD) had successfully the researcher to produce a simpler design of endotracheal tube holder (ETH) and to fabricate the prototype by using rapid prototyping. This would enhance the functions of the existing ETH to be more effective and efficient. 


\section{Acknowledgement}

The authors gratefully acknowledge the funding provided to this project by the Research Acculturation Grant Scheme (RAGS 12-050-0050) International Islamic University Malaysia and collaboration with Manufacturing Engineering Centre (MEC), Cardiff University, United Kingdom, a special note of thanks to Prof. D T Pham, at School of Mechanical Engineering, University of Birmingham,UK and to Dr Lee Chi Hew, University of Portsmouth, UK his assistant and for their expert guidance.

\section{References}

1. Thomas C. Mort and Jeffrey P. Keck $\mathrm{Jr}$.Endotracheal Tube and Respiratory Care; Handbook of Polymer Applications in Medicine and Medical Devices, 2013 Pages 191-230

2. V. Anne Hamilton, Mary Jo Grap, The role of the endotracheal tube cuff in microaspiration, Heart \& Lung: The Journal of Acute and Critical Care, Volume 41, Issue 2, March-April 2012, Pages 167-172

3. Ladan Ansari, Behnam Bohluli, Hamidreza Mahaseni, Naser Valaei, Pooyan Sadr-Eshkevari, Ashkan Rashad,The effect of endotracheal tube cuff pressure control on postextubation throat pain in orthognathic surgeries: a randomized double-blind controlled clinical trial, British Journal of Oral and Maxillofacial Surgery, Volume 52, Issue 2, February 2014, Pages 140-143
4. Jonathan T. Ketzler, Dennis F. Lander, Management of a severed endotracheal tube during LeFort osteotomy Journal of Clinical Anesthesia, Volume 4, Issue 2, March-April 1992, Pages 144-146

5. WAY Yusoff, Hasanudin Hafis Mohamad Ali, Md. Amir Hamzah Md. Shukri,A Surgical Training Maxillofacial Biomodel Manufacture Using Fused Deposition Modelling, Applied Mechanics and Materials, Vol. 576 (2012), pp633-636, ISSN: 16609336.

6. Shafie Kamaruddin, WAY Wan Yusoff, Abdul Hadi Mohamed, Design and Enhancement of Radiofrequency Cannula (RC) for Chronic Pain Management. 4th Mechanical and Manufacturing Engineering:Applied Mechanics and Materials. Vols. 465-466 (2014), pp 18-21, Trans Tech Publications, Switzerland, ISSN: 1660-9336 (http://www.scientific.net/AMM.465-466.18)

7. Kuen-Horng Tsai, Chun-Yu Yeh, Application of Quality Function Deployment in Design of Mobile Assistive Devices, Journal of Medical and Biological Engineering, Vol.28 (2008), pp87-93

8. Kriewall, T.J. ; Widin, G.P.An application of QFD to medical device development, medical Instrument design case studies, (1991),pp 23-36, IEEE Xplore. ISBN:0-7803-0627-9

9. Sharma J, Optimized design and development of a bio-medical healthcare device through quality function deployment (QFD). International Journal of Electronics Healthcare. 2012; 7(1):68-87. 